\title{
The Formation of Core Qualities of Teachers in Higher Vocational Colleges Under Big Data
}

\section{Li Zhen}

School of Business, Chongqing City Vocational College, Chongqing, China

\section{Email address:}

1848934829@qq.com.cn

\section{To cite this article:}

Li Zhen. The Formation of Core Qualities of Teachers in Higher Vocational Colleges Under Big Data. Science Innovation. Vol. 7, No. 1, 2019, pp. 7-9. doi: 10.11648/j.si.20190701.12

Received: January 21, 2019; Accepted: April 16, 2019; Published: April 28, 2019

\begin{abstract}
With the advent of big data era, network technology has gradually infiltrated into higher vocational education teaching work. In the context of big data, in the face of online open teaching resources, the role of teachers is faced with unprecedented challenges. Teachers should follow the development trend of big data, use data information technology to promote modern teaching mode, and realize The Times demand of data-driven teaching practice. In this regard, teachers in higher vocational colleges should follow the trend of The Times, update their inherent concepts, and use data technology to improve their big data literacy so as to better serve the teaching work. Based on the connotation of core quality of teachers in higher vocational colleges, this paper puts forward the basic requirements for core quality of teachers in the new era, so as to carry out targeted training and improve their professional knowledge and skills and data processing skills.
\end{abstract}

Keywords: Big Data, Higher Vocational Colleges, Core literacy

\section{大数据下高职院校教师核心素养的形成}

\section{李真}

重庆城市职业学院商学院, 重庆, 中国

\section{邮箱}

1848934829@qq.com.cn

\begin{abstract}
摘要：随着大数据时代的来临, 网络技术已逐步渗入到高职教育教学工作中来。在大数据背景下, 面对线上开放教学 资源, 教师角色受到前所未有的挑战, 教师应顺应大数据发展趋势, 利用数据信息技术促进现代化教学模式, 实现数 据驱动教学实践的时代诉求。在此之下, 高职院校教师应顺应时代潮流, 更新固有观念, 运用数据技术提升自身大数 据素养从而更好地服务于教学工作。本文从高职教师核心素养内涵出发提出新时代教师核心素养基本要求, 从而进行 针对性培养，提升自身专业知识技能及数据处理技能。
\end{abstract}

关键词: 大数据, 高职院校, 核心素养

\section{1. 引言}

《中共中央、国务院关于进一步加强人才工作的规定》 中强调：要“充分发挥高等职业院校的高级技工学校、技 师学院的培训基地作用, 扩大培训规模, 提高培训质量”。
高职院校作为高等教育发展中的一个类型,其目标就是要 培养面向生产、建设、服务和管理第一线需要的高技能人 才。这就要求与之匹配的高职教师队伍应是一支兼有过硬 的理论基础又有实践能力, 同时也应具有正确的理想信念 和高尚的品德, 从而指导一线教学、教育工作。 
随着科技的发展, 大数据时代的来临, 网络技术已 开始慢慢渗入人们的日常生活当中, 大数据思维改变着 人们的生活方式及工作方式。[5]信息技术已深入到教育 教学中来, 影响着教育的模式及评价方式。在大数据背 景下, 面对线上开放教学资源, 教师角色受到前所未有 的挑战, 教师应顺应大数据发展趋势, 利用数据信息技 术促进现代化教学模式, 实现数据驱动教学实践的时代 诉求。在此之下, 高职院校教师应顺应时代潮流, 更新 固有观念, 运用数据技术提升自身素养从而更好地服务 于教学。[1]

\section{2. 高职教师核心素养内涵}

高职院校教师的素质是制约高等职业教育质量和高 职院校可持续发展的关键。建设、培育高职教师的核心素 养是一切教育工作的核心。[7]

高职教师的核心素养是指作为高职教师在教书育人 过程中所表现出来的综合素质。包括师德、师风、专业技 能、创新意识及能力, 是高职教师内在的规范和要求, 影 响后天整体素养的形成和专业发展。大数据时代下, 高职 院校教师在拓宽自身专业素养的前提下, 信息素养及创新 意识是推动教师持续发展的必备条件, 与道德素养、人文 素养共同构成高职教师核心素养整体内容。[3]

\section{3. 大数据下高职教师面临的职业挑战}

\section{1. 传统教学方式已被信息化教学模式取代}

大数据环境下, 传统课堂面授已不能满足现代教学模 式。传统教学方式已被信息化教学模式所取代。教师在授 课环节中由主导变为辅助、引导, 学生在听课中由以往的 被动接收变为主动获取; 学生通过教师的辅助、引导主动 搜集信息、资料, 形成知识构建主体, 从而加深对新知识 的认识、理解, 形成自己的观点及思维模式; 教师在整个 教学过程中通过设定教学情境从中引导学生进行信息发 掘、问题探究、小组讨论、意义建构把学生推向学习的主 体地位; 新媒体也由教师讲解的演示工具转变为学生主动 学习、探究问题的助手, 帮助学生进行信息搜集、资料查 询。

\section{2. 传统教学评价已被多元化教学评价理念取代}

传统教学评价指针对特定的教学目标, 在某一理论的 指导下, 运用一定的方法手段, 对学生的学习结果进行评 估, 得出一个恰当的结论, 然后运用这个结论去分析教育 教学的现状, 进而提出治疗改进的措施。评价结果是相对 合理的。但这种固化的评价方式具有片面性, 已不适用于 信息化时代。大数据下多元化教学评价, 运用信息手段, 进行数据统计、分析, 多维度进行线上、线下教学测评, 使结论更具合理性, 评价结果能够多维度反映教学现象更 趋于真实。

\section{3. 海归教师大批涌入加速本土教师淘汰率}

随着80后、90后大批归国留学生源源不断地加入高职 教师队伍, 加剧了本土教师的职业竞争。海归教师以国际 化的视角、多元化的教学理念及多渠道的信息获取能力, 充分整合中国教育教学资源, 以最新的理念及开阔的思路 带给学生不一样的“国际化”课堂, 从而在专业技能及信息 获取上遥遥领先于本土教师。本土教师固化的思维模式和 教学方式适应不了 90 后的课堂需求, 从而加速了教师职业 淘汰率。

\section{4. 知识更迭使终身教育成为高职教师发展必然}

“终身教育”理念是当今教育领域传播最广、影响最大 的一种教育理念和思潮。终身教育为个人提供一生有组织 的学习机会, 使其不断学习、与时俱进, 全面提高个人素 养, 以适应社会发展所必需的一种教育理念。该理念打破 了传统的一次性教育定终身的观念, 认为教育不能只限于 人生的某一时期, 某一阶段, 而应贯穿人的整个一生。因 此, 对于高职教师来说, 在日常生活中应不断提升自身道 德修养; 在学习中应不断提高应用大数据进行搜集、检索 信息的能力; 在工作中不断创新教学模式, 持续地接受继 续教育才能适应飞速发展的人才需求。

\section{4. 大数据时代下高职教师核心素养形成}

\section{1. 提升搜集数据信息的意识与能力}

高职院校教师大数据素养的形成, 首先要强化教师对 于数据资源搜集、获取及使用意识。数据意识是衡量教师 “大数据素养”的标准之一。[12]具体主要是指教师在教学 环节中, 能否利用相关专业数据信息整合教育教学资源, 从而引导教学实践, 在实践中形成自身独特的数据意识。 [4]包括如何认识和辨别专业教育教学数据, 以及如何评定 教育数据对教学产生的相关价值、如何运用于教学实践等。 美国密西根大学建立的密西根大数据研究所研究发现, 教 师的教育数据意识与教师对大数据的转化能力是呈正比 关系的, 即:当教师的教育数据意识越强, 也就意味着教 师掌握数据的能力越强。从而加强教师大数据意识, 提升 信息甄别处理能力势在必行。

\section{2. 利用大数据提升自身专业水平}

深厚、广博的专业知识是高职教师立足之本。信息化 时代, 利用大数据甄别、汲取相关专业知识不断更新教学 内容, 从而强化自身专业水平。[8]

首先, 教师应具备搜集、甄别、学习网络资源的能力。 网络教学资源的获取可以使教师的知识储备得到更新, 不 断提高教师的专业知识修养, 还可以使教师随时了解学术 前沿动态, 紧跟学术发展的脚步。其次, 鼓励教师参加国 际间师资培训。[11]各级各类培训活动不仅能开阔眼界、 更新知识, 而且还能促进兄弟院校之间的合作、交流与学 习。[5]在大数据时代, 培训学习的形式也更加多样化。教 师可通过专家在线讲座、线上互动学习等模式进行多渠道 
学习, 使教师的专业知识水平得到提升, 更好地服务于教 学。[13]

\section{3. 大数据思维融入传统教学模式中}

教师大数据素养中的核心是构建大数据思维。培养教 师大数据思维，使教师运用线上 (云平台) 做数据统计分 析, 进行学生各类数据获取、分析、甄别, 使教育教学问 题更易凸显, 能够及时、迅速找到解决问题的方式、方法, 从而扩充传统教学模式, 使教学更有针对性。[9]从大数据 教育方法的模式上来看, 不同地区根据经济增速不同, 数 据教育方法模式也各有不同, 在实践教学进程中要注意以 现实刚性需求为导向, 分区域、分时段对数据教育方法进 行相应改革。[6]

\section{4. 行政部门利用大数据平台进行教师激励}

学校行政部门利用大数据平台进行教师激励, 具体从 三个方面进行：其一，通过主管部门牵头（教务处、教学 部)出台和制定相应的激励政策, 引导各方主体机构互联、 互动, 通过数据平台共享教师资料, 并做出科学决策使激 励政策落到实处。[2]其二，运用大数据平台（云平台）汇 聚的各类教学资源, 通过数据传输, 使教学资料在各系部、 各专业间流动、共享，从而提升同专业教师备课效率，相 互间及时进行探讨、沟通、交流，进而提高教学质量。其 三，各系部及行政部门在教师队伍建设和管理过程中，基 于大数据平台进行教师个人量化评估, 能够准确把握教师 的个人动态发展情况, 进行全方位、多视角掌握教师的主 观需求及个性化发展诉求, 正确引导教师个体全面发展, 提升教师管理水平。

\section{5. 结论}

面对大数据时代带来的社会教育变革, 高职院校教师 应不畏困难, 直面挑战, 转变陈旧思想观念及固化思维模 式, 利用网络数据平台进行知识更新, 不断学习国内外专 业新理论、新观点, 提升自身信息识别、汲取的能力, 不 断优化信息素养以及专业知识水平, 探索适应个人发展及 终身教育学习的网络途径, 从而更好地运用于教育、教学 工作。[10]学校行政部门及各职能部门也应利用数据平台 推动高职教师激励管理体制。以大数据技术为基础, 建设 适应本校的教师信息数据库, 全面掌握教师信息, 针对性 解决教师在教学、培训、管理过程中的各类难题, 实现全 程可控式、动态化的跟踪管理。[2]通过大数据激励进而优 化教师队伍, 提升本校教师整体职业素养。

\section{致谢}

本文为重庆市教育科学规划课题《新时期下高职院校 教师核心素养建设研究》(2017-GX-419)的阶段性成果之 一。感谢本项目在研究过程中学院科研处给予的配套经费 支持及全体主研人员在项目文献梳理、实地调研、论文撰 写中所做的辛苦努力。

\section{参考文献}

[1] 孙小琪.大数据环境下职业教育的发展与创新 [J].河北职业 教育, 2018(12):14-16.

[2] 张新昌. 大数据背景下高职教师精准培养的探索 [J]. 智库时 代, 2018(7):111-112.

[3] 徐炜,刘震. 大数据环境下高校青年教师专业发展路径[J].教 育教学论坛, 2018(11):3-4.

[4] 赵宴萍.大数据时代青年教师面临的机遇和挑战 $[\mathrm{J}]$.时代金 融,2018(9):328.

[5] 王红霞.大数据时代下教师角色转型研究 [J].陕西教育 (高 教),2018(9):36-37.

[6] 周杰龙.特征、走向与教育: 教师“大数据素养”历练[J].中国 成人教育,2018(18):143-144.

[7] 徐巧云.核心素养视域下教师专业核心能力发展研究[J].江 汉大学学报(社会科学版),2018(12):113-116.

[8] 王欣.高等职业技术院校青年教师核心素养发展研究 [J].职 业技术,2017(9):1-3.

[9] 陈卫东.面向未来的智慧教育教师素养提升探略[J].贵州师 范学院学报,2018(5):73-75.

[10] 索源. 高职院校技能大赛对青年教师核心素养推动作用的 研究[J].现代经济信息,2017(01):396.

[11] 柳清. 高职双语教师的核心素养及发展路径探究一以轨道 交通类高职院校为例 [J]. 岳阳职业技术学院学 报,2018(5):40-41.

[12] 宋艳艳.教育信息化背景下高职教师核心素养的培养路径 分析 [J].岳经贸实践,2018(2):260.

[13] 王陆. 大数据知识发现的教师成长行为路径 [J]. 电化教育研 究,2019(1):96-97. 